\title{
Preschool Behavioral and Social-Cognitive Problems as Predictors of (Pre)adolescent Disruptive Behavior
}

\author{
Alice Emond · Johan Ormel · René Veenstra · Albertine J. Oldehinkel
}

Published online: 3 May 2007

(C) Springer Science+Business Media, LLC 2007

\begin{abstract}
This article describes preschool social understanding and difficult behaviors (hot temper, disobedience, bossiness and bullying) as predictors of oppositional defiant disorder (ODD) and aggressive conduct disorder (ACD) in a Dutch population sample of (pre)adolescents $(N=1943)$, measured at age 10-12 and at age 13-15. ODD and ACD were assessed by the Child Behavior Checklist and the Youth Self-Report, preschool behavior was evaluated by the parental questionnaire 'How was your child as a preschooler? (age 4-5)'. Adjusted for each other, all difficult preschool behaviors except bullying were associated with adolescent ODD, while only bullying significantly predicted adolescent ACD. Furthermore, the results suggest a qualitative difference between ODD and ACD in terms of the social component of the disorders: poor preschool social understanding was associated with the development of ACD but not of ODD; and poor social understanding interacted with difficult preschool behaviors to predict later ACD but not ODD. The associations did not differ between boys and girls, and were roughly similar for preadolescent (age 10-12) and early adolescent (age 13-15) outcomes. The finding that poor social understanding was implicated in the development of ACD but not in the development of ODD may help to demarcate the individuality of each disorder and offer leads for (differential) treatment strategies.
\end{abstract}

Keywords Conduct disorder - Oppositional defiant disorder · Preschool children · Adolescence · Prospective study

\footnotetext{
A. Emond · J. Ormel · A. J. Oldehinkel $(\bowtie)$

Department of Psychiatry and Graduate School of Behavioral and Cognitive Neurosciences, University Medical Center Groningen, University of Groningen, P.O. Box 30001, Groningen 9700 RB, The Netherlands e-mail: a.j.oldehinkel@med.umcg.nl

R. Veenstra

Department of Sociology, University of Groningen, and Interuniversity Center for Social Science Theory and Methodology, Groningen, The Netherlands
}

\footnotetext{
A. J. Oldehinkel

Department of Child and Adolescent Psychiatry, Erasmus Medical Center, Rotterdam, The Netherlands
} 


\section{Introduction}

Oppositional defiant disorder (ODD) and conduct disorder (CD) are common disruptive behavioral disorders in adolescence, resulting in considerable impairment of functioning and high associated costs to society [1,2]. The DSM-IV [3] defines ODD and CD as two distinct constructs. ODD is characterized by a recurrent pattern of negativistic, defiant, disobedient, and hostile behavior toward authority figures, and CD by a repetitive and persistent pattern of behavior that violates the basic rights of others or age-appropriate societal norms or rules. Despite the fact that they are defined as two separate disorders, ODD and CD overlap and high comorbidity rates are reported in both clinical $[4,5]$ and general population samples [6-9]. The aim of the present study was to investigate general and specific associations of (retrospectively reported) preschool difficult behaviors and social understanding with ODD and CD symptoms during preadolescence (10-12 years) and early adolescence (13-15 years).

ODD and CD: distinct developmental pathways?

The boundaries between ODD and CD have been strongly debated [10]. Whilst some authors argue that the distinction between the conditions is mainly based on severity, with ODD representing a milder variant of $\mathrm{CD}$, a growing body of research suggests differences in the developmental pathways of these two disorders [4, 7, 8, 11-13]. If this is the case, external correlates and their differential associations with ODD and CD could help to distinguish between these conditions [14].

Symptoms of CD include both behaviors that violate age-appropriate societal norms or rules, such as obscene language and truancy, and aggressive behaviors that violate the basic rights of others, that is, threatening, cruelty, assault, fighting and stealing. In particular the latter, referred to as aggressive CD symptoms (ACD), are assumed to be qualitatively different from oppositional defiant symptoms. ACD symptoms involve direct cruelty and harm to others, in other words, behaviors characterized by little compassion for other people's feelings and emotions. This lack of empathy might be due to deficits in social understanding [11].

As opposed to ACD, ODD involves behaviors predominantly directed against authority figures. Deficits in social understanding are less likely to play a role here. Rather, ODD problems seem to be primarily related to impairments in affective modulation and selfregulation, which decrease the ability to remain controlled when provoked, and to comply with rules that interfere with one's own goals $[11,15]$.

Preschool difficult behaviors as predictors of later disruptive behaviors

Children with serious disruptive behavioral problems (DBP) often show difficulties dating back to their preschool years [16-18]. Preschool difficult behaviors such as self-regulation problems and non-compliance may reflect normative, age-related developmental transitions [16], but severe and persistent problem behaviors in a young child suggest the onset of a behavioral disorder [19]. A large body of evidence supports continuity of DBP from preschool years, through childhood, to adolescence [16, 20-25]. Compared to later-onset problems, behavioral problems with an onset in early childhood are more likely to reflect 
fairly stable, possibly genetically determined features such as hyperactivity, adverse temperament, self-regulation problems, and cognitive difficulties [26, 27]. Stable risk factors imply a relatively high probability of persistence or recurrence of behavioral problems. Continuity of DBP may also result from negative spirals of undesirable behaviors provoking negative reactions from others, which further aggravate the child's distress and reduce opportunities to deal with environmental challenges in an adaptive, non-disruptive way [27-30].

Preschool difficult behaviors tend to co-occur [16] and therefore are often grouped together in research on trajectories of disruptive behaviors. Although an overall measure of early problem behaviors may predict later psychiatric disorders better than isolated behaviors [16, 18], grouping various preschool behaviors together runs the risk of overlooking specific associations that may be relevant in distinguishing between behavioral disorders such as ODD and (A)CD. To date, little is known about how individual behaviors in the preschool period can predict ODD and ACD problems in adolescence.

\section{Social interaction and disruptive behaviors}

DBP can impact on adolescents' social interactions with peers, family members and teachers [14]. Literature on these disorders suggests that difficulties in social relationships stem back to early childhood [31]. In general, children with DBP have poorer social relationships than non-disruptive peers, seen in discordant interactions and frequent peer rejection $[16,19,32,33]$. These problems continue into adolescence. The nature of social interaction problems of children with DBP is qualitative rather than quantitative: they make the same number of attempts at social interaction with their peers, but their overtures are less successful [34]. A probable reason for this is that disruptive children have social skill deficits: they lack the positive communication skills required for successful group interactions [35], and are less likely than other children to be prosocial [36].

Children's social skills and peer interactions are affected by their level of social understanding, that is their ability to read and interpret social situations accurately [37]. The social information processing (SIP) model of aggressive behavior [38, 39] postulates that aggressive children have processing biases in the encoding and interpretation of social cues, resulting in aggressive responses. In support of the SIP model, studies have shown that, in contrast to non-aggressive peers, aggressive children underutilize social cues, are less empathic, and selectively attend to hostile stimuli [27, 40, 41]. Consequently, they frequently misunderstand peers' intentions and adopt a hostile attribution bias, which leads to reactive aggression in response to minor provocation [42]. These social cognitive biases not only reinforce and exacerbate aggressive behavior throughout childhood [43], but also increase the likelihood of peer rejection [44, 45], which is strongly associated with the development of DBP [28, 46], over and above the effects of aggression [47].

Social understanding is supposed to play a bigger role in the development of ACD than of ODD, because the latter is primarily directed towards authority figures and hence less likely to be the result of problematic peer interactions. Besides, as mentioned before, the lack of compassion for other people's feelings and emotions that characterizes ACD symptoms seems to reflect deficits in social understanding. 
Age

Several longitudinal studies have indicated etiological differences between life-coursepersistent (childhood-onset) and adolescence-limited (adolescent-onset) CD [48, 49]. Moffitt and colleagues [49, 50] found that early childhood temperament and problem behaviors were associated with life-course-persistent problems, but not with adolescencelimited problems. Hence, the age at which the disruptive behavior is measured might influence the strength of the association with early childhood behaviors, more specifically, preadolescent disruptive behaviors are likely to have stronger associations with preschool behaviors than (early) adolescent behaviors due to adolescent-onset cases without early childhood risk factors.

\section{Present study}

The aim of the present study was to investigate to what extent preschool difficult behaviors and social cognition predicted ODD and ACD symptoms in preadolescents (10-12 years) and early adolescents (13-15 years) from the general population. In particular, we were interested in the role of particular preschool behaviors (hot temper, disobedience, bossiness and bullying) and early social understanding in distinguishing between later ODD and ACD symptoms. We hypothesized that (pre)adolescents with ACD symptoms would show greater deficits in preschool social understanding than those with behaviors typical of ODD. Especially the combination of low social understanding and difficult behaviors was expected to increase the probability of later ACD symptoms. Hence, we hypothesized that the interaction between difficult preschool behaviors and early social understanding would predict later ACD, but not ODD. Finally, we expected that preschool behaviors would be more strongly associated with preadolescent than with adolescent disruptive behaviors.

\section{Method}

Sample and procedure

Participants were members of the TRacking Adolescents' Individual Lives Survey (TRAILS), an ongoing cohort study based on a sample representative of the Dutch population, investigating the development of mental health from preadolescence into adulthood. The present study used data from the first (T1) and second (T2) assessment wave of TRAILS, which ran from March 2001 to July 2002, and September 2003 to December 2004, respectively.

Sample selection involved two steps. First, five municipalities in the North of the Netherlands, including both urban and rural areas, were requested to give names and addresses of all inhabitants born between 10-01-1989 and 09-30-1990 (first two municipalities) or 10-01-1990 and 09-30-1991 (last three municipalities), yielding 3483 names. Simultaneously, primary schools (including schools for special education) within these municipalities were approached with the request to participate in TRAILS; that is, provide information about TRAILS participants' behavior and performance at school and allow class administration of questionnaires and individual testing at school. Of the 135 primary schools within the municipalities, 122 (90.4\% of the schools accommodating $90.3 \%$ of the children) agreed to participate in the study. 
If schools agreed to participate, eligible children and their parents (or guardians) received brochures with information about the study and a TRAILS staff member visited the school to provide additional details. Shortly thereafter a TRAILS interviewer contacted parents by telephone to ask whether they and their son or daughter were willing to participate in the study. Respondents with an unlisted telephone number were requested by mail to pass on their number. If they reacted neither to that letter, nor to a reminder letter sent a few weeks later, staff members paid personal visits to their house. Parents who refused to participate were asked for permission to call back in about two months to minimize the number of refusals due to temporary reasons. Of all children approached for enrollment in the study (i.e., selected by the municipalities and attending a school that was willing to participate, $N=3145$ ), $6.7 \%$ were excluded because of mental or physical incapability or language problems. Of the remaining 2935 children, 76.0\% $(N=2230$, mean age $=11.09, S D=0.55,50.8 \%$ girls) were enrolled in the study, that is, both child and parent agreed to participate. Parental written informed consent was obtained after the procedures had been fully explained. Responders and non-responders did not differ with respect to the prevalence of teacher-rated problem behavior. Furthermore, no differences between responders and nonresponders were found regarding associations between sociodemographic variables and mental health outcomes [51].

The follow up assessment (T2) was held two to three years (mean number of months 29.44, $S D=5.37$, range 16.69-48.06) after the baseline assessment (T1), and included $96.4 \%$ of baseline participants $(N=2149$, mean age $13.56, S D=0.53,51.0 \%$ girls $)$. Adolescents with many ACD problems at T1 had a somewhat higher probability of attrition than those with lower levels ( $\mathrm{OR}=1.3, p=.003$, standardized scores). Missingness at T2 was not related to gender or to T1 ODD symptoms. We excluded 29 adolescents with missing or non-reliable data on disruptive behavior problems at either $\mathrm{T} 1$ or T2, and 177 adolescents with missing preschool behavior data at T1, leaving 1943 to be included in the analyses.

Measures

\section{Adolescent disruptive behaviors}

Both at $\mathrm{T} 1$ and $\mathrm{T} 2$, disruptive behavioral problems were assessed by the Child Behavior Checklist (CBCL), one of the most commonly used questionnaires in current child and adolescent psychiatric research [52]. The CBCL contains a list of 120 behavioral and emotional problems, which parents can rate as $0=$ not true, $1=$ somewhat or sometimes true, or $2=$ very or often true in the past six months. In most cases $(96 \%)$, the informant was the child's mother. In addition to the CBCL, we administered the self-report version of this questionnaire, the Youth Self-Report (YSR [53]). In addition to the original CBCL/ YSR scales, Achenbach and colleagues [54] developed DSM-IV scales that corresponded more closely to clinical diagnostic categories. The scale for ODD comprises five items (Cronbach's $\alpha \mathrm{CBCL}=0.77, \mathrm{YSR}=0.62$ ). The mean item score at $\mathrm{T} 1$ was 0.58 $(S D=0.42$, range $0-2)$ for the CBCL-scale and $0.44(S D=0.35$, range $0-1.8)$ for the YSRscale. At T2 the mean item score was $0.42(S D=0.39$, range $0-2)$ for the CBCL-scale and $0.45(S D=0.35$, range $0-2)$ for the YSR scale. With a few exceptions, the percentages of (pre)adolescents endorsing each of the ODD symptoms ranged between $30 \%$ and $60 \%$.

The DSM-IV scale for CD comprises 17 (CBCL) or 15 (YSR) items [54]. From these, we selected 6 items (present in both questionnaires) as specifically reflecting ACD 
symptoms, that is, behaviors that violate the basic rights of others. These items were being cruel/mean to others, bullying, destroying things belonging to others, fighting a lot, physically attacking people, stealing outside the home, and threatening people. To ensure that these symptoms represented a different dimension than the ODD symptoms, factor analyses (two factors, promax rotation) were performed on the five ODD symptoms and the six ACD symptoms for each informant (parent, child) and measurement (T1, T2). Although the CBCL and YSR scores at T1 and T2 showed some relatively minor differences, the factor loadings generally reflected the assumed distinction between ODD and ACD. Table 1 shows the factor loadings based on the mean item scores across informants and measurements. The item 'being cruel/mean to others' had relatively high loadings on both factors. This is probably due to the fact that it had a relatively high prevalence, because of which part of its variance could not be explained by the other, more severe, ACD symptoms. The item was maintained in the selection of ACD symptoms because conceptually it is an evident example of behaviors that are harmful to others. The variance explained by the two factors was $51.2 \%$. The mean item score at T1 was 0.09 ( $S D=0.18$, range 0-1.7) for the CBCL-ACD scale and $0.14(S D=0.22$, range 0-1.5) for the YSRACD scale. At T2 the mean item score was 0.05 ( $S D=0.13$, range $0-1.5)$ for the CBCLACD scale and $0.13(S D=0.19$, range $0-1.8)$ for the YSR-ACD scale. As indicated by the relatively low mean item scores, the prevalence of the ACD symptoms was considerably lower than that of the ODD symptoms, and the percentage of (pre)adolescents endorsing each of the ACD symptoms ranged between $37 \%$ to less than $2 \%$. The reliabilities (Cronbach's $\alpha$ ) were 0.66 (T1 CBCL), 0.64 (T1 YSR), 0.64 (T2 CBCL), and 0.60 (T2 YSR).

The agreement between parent-reported (CBCL) and adolescent-reported disruptive behavior (YSR) problems was moderate (T1: ODD $r=.30$, ACD $r=.30$; T2: ODD $r=.35$, ACD $r=.33$ ). The mean standardized parent and adolescent scores were used as a measure of ODD and ACD in this study. These measures correlated highly ( $\geq .94)$ with the composite scores based on the highest (standardized) score of both informants. When CBCL/YSR data of one informant were missing or unreliable (missing YSRs: T1: $n=30$, T2: $n=32$; missing CBCLs: T1: $n=2$, T2: $n=144$ ), the composite score was based on only one informant.

Table 1 Two factor pattern matrix for oppositional defiant disorder (ODD) and aggressive conduct disorder (ACD) symptoms

\begin{tabular}{lll}
\hline Item & Loading on factor 1 & Loading on factor 2 \\
\hline ODD Argues a lot & .66 & \\
Disobedient at home & .77 & \\
Disobedient at school & .44 & \\
Stubborn/irritable & .77 & \\
Temper tantrums/hot temper & .48 & .39 \\
ACD Cruel/mean to others, bullying & .33 & .51 \\
Destroys others' belongings & & .66 \\
Fights a lot & & .74 \\
Physically attacks people & & .46 \\
Steals outside the home & & .64 \\
Threatens people & & \\
\hline
\end{tabular}

The table displays only loadings $>.30$ 


\section{Preschool behaviors}

Preschool behaviors were assessed retrospectively by parents at $\mathrm{T} 1$, using the questionnaire 'How was your child as a preschooler? (age 4-5)'. The questionnaire contains a list of 17 behavioral, emotional and motor items, which parents can rate on a fivepoint scale in relation to their child's peers; $1=$ a lot less than average, $2=$ less than average, $3=$ average, $4=$ more than average, $5=$ a lot more than average. Four items were selected as representing difficult preschool behaviors: hot temper, disobedience, bullying, and bossiness. Factor analysis (promax rotation) had revealed that these four behaviors made up a separate factor. We also constructed an overall preschool difficult behavior scale by averaging the items scores (Cronbach's $\alpha=0.70$ ). The item 'Was your child able to sense social situations well' was used as a measure of the preschoolers social understanding. The term 'social understanding' is used in this paper to reflect a person's ability to accurately perceive, interpret and grasp the nature of social interactions.

\section{Analysis}

First, we examined bivariate associations between preschool behaviors and ODD and ACD symptoms at T1 and T2. Multiple linear regression analyses were then used to test the associations between preschool difficult behaviors and preschool social understanding on adolescent ODD and ACD, adjusted for gender and the other kind of disruptive behaviors (i.e., the effects on ODD were adjusted for ACD and vice versa). Preschool difficult behaviors, social understanding and their interaction were entered in the first step, and interactions of preschool behaviors and gender were entered in the second step. All continuous variables were standardized to mean 0 and standard deviation 1 in the regression analyses, to ease interpretation of the coefficients and avoid multicollinearity in the regression. Analyses were performed with both T1 and T2 ODD/ $\mathrm{ACD}$ as outcome variables. However, as associations between preschool behaviors and T1 outcomes were more likely to be inflated by informants' bias, we decided to present data on T2 outcomes only, and where T1 results deviated from T2 outcomes describe the differences. Finally, to examine the specificity of the effects for ACD as compared to other CD symptoms (reflecting violation of age-appropriate societal norms or rules), we repeated the above-described analyses with the full $\mathrm{CD}$ scale as outcome variable, adjusting for the ACD symptoms. A p-value smaller than .01 was considered statistically significant.

\section{Results}

Descriptive statistics

Table 2 presents the distribution of preschool behaviors and adolescent disruptive behavioral problems (ODD and ACD) at both assessment waves (T1 and T2). The variables reflect the mean of the scale items (range: preschool variables 1-5, adolescent ODD/ ACD scores 0-2).

The correlations between these variables are presented in Table 3. Preschool difficult behaviors were moderately associated with disruptive disorders in (pre)adolescence, with 
Table 2 Mean and standard deviation of Preschool behaviors and (pre)adolescent oppositional defiant disorder (ODD) and aggressive conduct disorder (ACD) problems $(N=1943)$

\begin{tabular}{|c|c|c|}
\hline & Mean & $S D$ \\
\hline Preschool difficult behavior Scale & 2.56 & 0.65 \\
\hline Hot temper & 2.65 & 1.01 \\
\hline Disobedience & 2.88 & 0.74 \\
\hline Bullying & 2.13 & 0.86 \\
\hline Bossiness & 2.60 & 0.95 \\
\hline Preschool social understanding & 3.24 & 0.78 \\
\hline \multicolumn{3}{|c|}{ Adolescent disruptive behavioral problems } \\
\hline ODD T1 ${ }^{\mathrm{a}}$ & 0.51 & 0.31 \\
\hline $\mathrm{ACD} \mathrm{T} 1^{\mathrm{a}}$ & 0.11 & 0.16 \\
\hline ODD $\mathrm{T}^{\mathrm{a}}$ & 0.44 & 0.31 \\
\hline $\mathrm{ACD} T 2^{\mathrm{a}}$ & 0.09 & 0.14 \\
\hline
\end{tabular}

a Mean of unstandardized parent and self-report scores

Table 3 Correlations between preschool behaviors, oppositional defiant disorder (ODD) problems and aggressive conduct disorder (ACD) problems at T1 and T2, adjusted for gender $(N=1943)$

\begin{tabular}{|c|c|c|c|c|c|c|c|c|}
\hline & $\begin{array}{l}\text { Hot } \\
\text { temper }\end{array}$ & Disobedience & Bullying & Bossiness & $\begin{array}{l}\text { Social } \\
\text { understanding }\end{array}$ & $\begin{array}{l}\text { ODD } \\
\text { T1 }\end{array}$ & $\begin{array}{l}\text { ACD } \\
\text { T1 }\end{array}$ & $\begin{array}{l}\text { ODD } \\
\text { T2 }\end{array}$ \\
\hline Hot temper & - & & & & & & & \\
\hline Disobedience & .36 & - & & & & & & \\
\hline Bullying & .43 & .29 & - & & & & & \\
\hline Bossiness & .44 & .25 & .48 & - & & & & \\
\hline $\begin{array}{l}\text { Social } \\
\quad \text { understanding }\end{array}$ & -.18 & -.26 & -.18 & -.08 & - & & & \\
\hline ODD T1 & .36 & .28 & .23 & .27 & -.15 & - & & \\
\hline ACD T1 & .22 & .21 & .29 & .19 & -.18 & .56 & - & \\
\hline ODD T2 & .25 & .22 & .17 & .22 & -.12 & .53 & .34 & - \\
\hline ACD T2 & .19 & .18 & .21 & .17 & -.15 & .39 & .56 & .56 \\
\hline
\end{tabular}

All correlations were significant at $p<.01$

somewhat higher correlations for T1 than for T2 outcomes. Except for bullying, correlations with ODD were higher than those with ACD. Preschool social understanding showed relatively weak associations with ODD and ACD, in particular ODD. High correlations between ODD and ACD suggest considerable comorbidity of the two conditions.

Preschool predictors of adolescent ODD and ACD

Table 4 shows the main effects and interactions of preschool difficult behaviors and preschool social understanding with ODD or ACD at T2 as outcome variables, adjusted for gender and the other outcome (i.e., the effects for ODD were adjusted for ACD and vice versa). Preschool difficult behaviors predicted both ODD and ACD problems in adolescence. Early social understanding was associated with ACD but not with ODD. Interaction 
Table 4 Regression model showing effects of preschool difficult behaviors, social understanding and their interactions on ODD and ACD at T2 $(N=1943)$

\begin{tabular}{|c|c|c|c|c|}
\hline & \multicolumn{2}{|c|}{$\mathrm{T} 2 \mathrm{ODD}\left(R^{2}=.35\right)$} & \multicolumn{2}{|c|}{$\mathrm{T} 2 \operatorname{ACD}\left(R^{2}=.36\right)$} \\
\hline & $B$ & $p$ & $B$ & $p$ \\
\hline $\mathrm{T} 2 \mathrm{ACD}$ & 0.54 & $<.001$ & - & \\
\hline T2 ODD & - & & 0.53 & $<.001$ \\
\hline Gender (male) & -0.25 & $<.001$ & 0.33 & $<.001$ \\
\hline Preschool disruptive behaviors & 0.17 & $<.001$ & 0.06 & .001 \\
\hline Preschool social understanding & -0.01 & .609 & -0.06 & .002 \\
\hline Preschool social understanding $\times$ disruptive behaviors & -0.00 & .762 & -0.05 & $<.001$ \\
\hline
\end{tabular}

effects between preschool social understanding and difficult behaviors were found with respect to ACD but not ODD. None of the interactions between gender and preschool behaviors were statistically significant. Adjusted for gender and ACD respectively ODD, preschool behaviors explained $2.7 \%$ of the variance in ODD problems and $1.2 \%$ of the variance in ACD problems.

Individual difficult behaviors

Hot temper, disobedience, and bossiness were all significant predictors of ODD problems ( $B \mathrm{~s}$ between 0.12 and $0.14, p s<.001)$, while the association with bullying was marginally significant $(B=0.05, p=.01)$. When all preschool behaviors were included in the model simultaneously, the effects of hot temper, disobedience, and bossiness remained significant ( $B$ s between 0.08 and $0.10, p s<.001$ ), while the effect of bullying showed a trend in the opposite direction $(B=-0.05, p=.02)$. ACD was only significantly predicted by preschool bullying $(B=0.10, p<.001)$; the other associations showed a trend (all $B \mathrm{~s}=.04$, $p$ s between .02 and .05). When the effects of all preschool difficult behaviors were adjusted for each other, bullying remained significantly associated with ACD problems $(B=0.11, p<.001)$, while the effect of other behaviors had disappeared ( $B$ s between -0.01 and 0.02 , all $p$-values $>.41$ ). With regard to ODD, none of the preschool difficult behaviors interacted with early social understanding (all $p$-values $>.29$ ). With regard to ACD, significant interactions were found for bullying $(B=-0.08, p<.001)$ and bossiness $(B=-0.05, p<.01)$, while a trend was seen for disobedience and hot temper $(B=-0.03, p=.04$ for both behaviors).

Preadolescence versus early adolescence

Comparable to T2, preschool difficult behaviors predicted ODD at T1, and neither the main effect of social understanding nor the interaction of social understanding and preschool difficult behaviors was significant. Also comparable to T2, all individual preschool difficult behaviors were significantly related to T1 ODD problems, and the sign of the effect of bullying was reversed when adjusting for other preschool behaviors. As concerning T1 ACD problems, most results were similar to those regarding T2 problems, but the interaction effect of preschool social understanding and difficult behaviors failed to reach statistical significance at T1 $(B=-0.02, p=.07)$. Similarly, although the results suggest an 
interaction effect for bullying $(B=-0.04, p=.02)$, none of the interactions with individual preschool difficult behaviors was significant.

\section{$\mathrm{ACD}$ versus $\mathrm{CD}$}

Using the full CD scale as the outcome variable instead of the ACD scale yielded effects that were roughly similar but slightly weaker than to the ones presented in Table 4, with a trend for the main effect of social understanding $(B=-0.03, p=.034)$ and a significant interaction of social understanding and difficult behaviors $(B=-0.04, p=.005)$. However, these effects disappeared (main effect: $B=0.00, p=.985$; interaction: $B=-0.00, p=.673$ ) when adjusting for ACD symptoms; indicating that the association between CD and early social understanding was fully accounted for by the ACD symptoms.

\section{Discussion}

\section{Main findings}

The aim of this study was to investigate to what extent early social understanding directly and in interaction with preschool difficult behaviors predicted symptoms of ODD and ACD during pre- and early adolescence. In addition, we were interested in the role of particular preschool behaviors (hot temper, disobedience, bossiness and bullying) in distinguishing between later diagnoses of ODD and ACD. We hypothesized that (1) adolescents with ACD symptoms would show greater deficits in preschool social understanding than those with behaviors typical of ODD, and (2) preschool difficult behaviors would interact with early social understanding to predict later ACD but not ODD. Both hypotheses were fully supported by our results, suggesting that social understanding is a major distinguishing factor between ODD and ACD. The findings were specific for aggressive CD symptoms, as opposed to CD symptoms reflecting violation of age-appropriate societal norms or rules. Analysis of the individual preschool difficult behaviors indicated a difference between bullying on the one hand and hot temper, disobedience, and bossiness on the other hand: adjusted for each other, all behaviors except bullying increased the probability of later ODD, but only bullying significantly predicted ACD. None of the individual preschool difficult behaviors interacted with social understanding to predict later ODD. Regarding ACD, social understanding significantly interacted with bullying and bossiness to predict later ACD, while a trend was found for the interaction between social understanding, and, respectively, disobedience and hot temper. As opposed to our expectations, the effects were largely similar for preadolescent and early adolescent outcomes, except that the social component of ACD seemed somewhat weaker in preadolescents (no significant interaction of social understanding and preschool difficult behaviors).

Preschool disruptive behaviors, preschool social cognition and adolescent ODD/ACD

Our finding that preschool difficult behaviors were collectively associated with both adolescent ODD and adolescent ACD is consistent with earlier reports on the continuity of difficult behavior from preschool years through childhood into adolescence [21, 25], and shows that this continuity is not restricted to a specific outcome. 
Poor early social understanding predicted ACD but not ODD, which supports the argument that ACD symptoms fundamentally reflect a lack of empathy for others, associated with an early deficit in social understanding [11]. Impairment in children's ability to accurately read or interpret social situations can lead to reactive aggression through the misattribution of hostility to others' behavior [38, 39]. In addition to directly leading to aggression, poor social understanding can reinforce and exacerbate aggressive behavior throughout childhood [43]. Peer rejection may be an important mediator in the link between difficulties in social understanding and the development of aggressive disruptive behavior [45], and may further interfere with the development of social understanding [31]. Peer rejection generally leads to relationships of lesser quality and hence reduces options to learn from peer experiences. In turn, this may devalue the motivation to preserve peer relationships, thereby increasing the probability of aggression as a strategy to achieve one's goals.

Adjusted for ACD, preschool social understanding did not predict ODD, neither as a main effect nor in interaction with difficult behaviors. This is consistent with results found in a clinical sample by Green and colleagues [11], who identified social impairments as an important distinguishing factor between subjects with ODD alone and those with comorbid CD. Hence, ODD symptoms may result from a wide range of social and psychobiological risk factors (notably problems with affective modulation and self-regulation [15]), but difficulties in understanding social clues do not seem to be among them.

\section{Individual preschool difficult behaviors}

Whereas all individual preschool difficult behaviors except bullying were significant predictors of ODD, only bullying directly predicted ACD. The finding that early bullying predicts the development of later ACD is in line with previous research that reports increased conduct problems in children who are involved in direct bullying [55]. Whilst research with young children is limited, bullying in primary school shows continuity into adolescence [56] and is recognized as an early indicator of persistent conduct problems.

Bullying can be considered a specific kind of aggression, in that it is social in nature and context $[57,58]$, and involves an intent to cause harm to the victim [59,60]. The traditional social cognitive approach to aggression explains bullying as a social cognitive deficit, with bullies' poor social understanding being central to their hurtful behavior [38]. Our finding that early bullying interacted with poor social understanding in the development of ACD supports this view, and suggests continuity of cruel and harmful behavior from preschool age into adolescence. In contrast, however, it has also been argued that 'pure' bullies are 'skilled manipulators' who use their cool cognition (superior social cognitive skills combined with low empathic disposition) to manipulate and dominate others to inflict suffering. A review of the literature on subgroups of bullying [58] suggests that the children who show both aggressive behavior and poor social understanding are likely to not only bully other children, but be victimized by others as well (bully/victims). Bully/victims have been reported to have a higher probability to develop conduct problems than 'pure' bullies [55, 61, 62]. Most likely, the children identified as preschool bullies in our study fit the profile of bully/victims better than that of skilled manipulators, not only because of their young age, but also because some parents may have interpreted preschool bullying as aggressive behavior in general, rather than as harmful acts directed towards specifically selected victims. Furthermore, Veenstra et al. [63] reported moderate associations between 
preschool bullying and victimization in our sample, supporting the notion that a sizeable group of the preschool bullies in our study were also victims.

Adjusted for other preschool difficult behaviors, bullying was not associated with ODD problems. This suggests that the component of preschool bullying not shared with other preschool difficult behaviors is specifically associated with aggressive conduct problems, and not with oppositional defiant behaviors.

Is it useful to distinguish between preschool behaviors or are they all part of a spectrum of difficultness? Our results showed there is not much point in differentiating between preschool hot temper, disobedience, and bossiness. Preschool bullying on the other hand, alone and in interaction with poor social understanding, seems to reflect a specific aspect of difficult behaviors which highlights the difference in the social component between adolescent ODD and ACD.

\section{Preadolescent and early adolescent ODD and ACD}

Our results showed no major differences between preadolescent and early adolescent outcomes. Correlations between preschool variables and disruptive behavior problems were somewhat higher at preadolescence than at early adolescence. This could reflect inflated association resulting from the simultaneous assessment of preschool and preadolescent behaviors. The weaker associations at adolescence could also denote the presence adolescent-onset cases, assumed to be less related to early-childhood risk factors [26]. At any case, the differences were marginal. Adolescence-limited conduct problems have been defined as disruptive behavior emerging at age 15-18 years, due to a gap between biological and social maturity [26]. The relatively low age of our participants at the second assessment wave (average 13.6 years) and the lack of increase in the number of disruptive problems between the first and second wave suggest that we may have been too early to measure any potential age effects. Apart from the slightly higher correlations at preadolescence, the only difference between associations with preadolescent and adolescent outcomes was that the interaction between social understanding and preschool difficult behavior was significant in adolescence, but not in preadolescence. This could indicate that social skills are gaining importance during early adolescence. However, the age-related differences were so small that we feel it would be overly speculative to expand on this issue.

Strengths, limitations, and recommendations for future research

Important strengths of this study are that it was based on a large representative population sample of (pre)adolescents, and involved multiple informants. Furthermore, the mental health questionnaires (CBCL/YSR) used allowed us to create DSM-IV-based ODD and (A)CD scales, and assess qualitative differences between the two disorders. The main limitation of the study is that preschool variables were retrospectively reported, more than five years later at preadolescence. Although we mainly presented data on adolescent ACD and ODD to reduce the risk of inflated associations due to simultaneous data collection, retrospective data have clear weaknesses and we do not know how well parents can judge preschool behaviors several years later. Besides recall biases, parents' reports may be prejudiced by their own norms and attitudes regarding normal and deviant (social) behaviors and functioning. In addition, we used only one measure of preschool social 
understanding, of unknown validity, which limits the discussion of the precise social deficits involved in the development of ACD. On the other hand, the significance of a single item in qualitatively differentiating between the development of ACD and ODD should also be noted as a strength of this study.

Although the current study results, due to lack of prospective data, are inconclusive regarding the exact relationship between preschool behaviors and the development of ACD and ODD, they provide clues for the distinction between ODD and ACD: although both ODD and ACD are disruptive behavioral disorders, with ACD reflecting an increased level of severity, they may be qualitatively different in terms of the social component of the disorder.

Tentatively, the association between preschool behavioral difficulties and adolescence disruptive behavioral problems found in our and previous studies hints that early intervention programs for difficult preschoolers could be beneficial to prevent nonadaptive developmental trajectories. Particularly efforts to increase self-regulation skills may be effective in this respect. Children with impaired social skills deserve special attention. Considering that poor social understanding not only has an effect on the development of ACD in its own but also amplifies the risk associated with difficult preschool behaviors, early intervention programs aimed at improving social understanding in children with deficits in this domain might prevent negative spirals of aggression and rejection leading to severe behavioral problems.

It should be noted that the effects found in this study were small and call for replication in other samples. In addition, the results have highlighted areas that need further research. First, prospective studies starting in preschool years and continuing throughout adolescence are required in order to examine the relationship between social understanding and specific disruptive behavioral disorders in more detail and avoid recall bias. Observations of actual preschool behaviors or the use of (preschool) educators as informants may prevent parent-related biases due to family norms about appropriate behaviors. Second, research is called for that includes further measures of social understanding to establish the nature of the social deficits involved, for instance by using various theory of mind tasks [64]. Third, our findings suggest that early invention programs may reduce the likelihood of later disruptive behavior problems in difficult preschoolers, but more research is needed to establish the feasibility of such programs, the specific groups that should be targeted, and the clinical relevance of the outcomes.

\section{Summary}

This article describes preschool social understanding and difficult behaviors (hot temper, disobedience, bossiness and bullying) as predictors of symptoms of ODD and ACD in a Dutch population sample of (pre)adolescents. All difficult preschool behaviors except bullying were associated with adolescent ODD, while only bullying significantly predicted adolescent ACD. Furthermore, the results suggest a qualitative difference between ODD and $\mathrm{ACD}$ in terms of the social component of the disorders: poor preschool social understanding was associated with the development of ACD but not of ODD; and poor social understanding interacted with difficult preschool behaviors to predict later ACD but not ODD. The findings were specific for aggressive CD symptoms, as opposed to CD symptoms reflecting violation of age-appropriate societal norms or rules. The finding that deficient social skills were implicated in the developed of ACD but not in the development of ODD may help to demarcate the individuality of each syndrome. Major differences were 
found neither between boys and girls, nor between preadolescent and early adolescent outcomes. The results suggest that early intervention programs for difficult preschoolers might be beneficial to prevent nonadaptive developmental trajectories, and that children with impaired social skills deserve special attention because mutual reinforcement of aggression and rejection may lead to increasingly severe behavioral problems.

Acknowledgments This research is part of the TRacking Adolescents' Individual Lives Survey (TRAILS). Participating centers of TRAILS include various Departments of the University of Groningen, the Erasmus Medical Center of Rotterdam, the University of Nijmegen, the Trimbos Institute, and the University of Utrecht, The Netherlands. TRAILS is financially supported by grants from the Netherlands Organization for Scientific Research (GB-MW 940-38-011, GB-MAG 480-01-006, ZonMw 100.001.001; NWO 175.010.2003.005) and the Department of Justice (WODC), and by the participating centers.

\section{References}

1. Frick PJ (2001) Effective interventions for children and adolescents with conduct disorder. Can J Psychiatry 46:597-608

2. Lahey BB, Loeber R, Quay HC, Frick PJ, Grimm J (1997) Oppositional defiant disorder and conduct disorder. In: Widiger TA, Frances AJ, Pincus HA, Ross R, First MB, Davis W (eds) DSM-IV Sourcebook, vol. 3. American Psychiatric Press, Washington DC, pp 189-209

3. American Psychiatric Association (1994) Diagnostic and statistical manual of mental disorders, 4th edn. American Psychiatric Association, Washington, DC

4. Lahey BB, Loeber R, Quay HC, Frick PJ, Grimm J (1992) Oppositional defiant and conduct disorders: Issues to be resolved for DSM-IV. J Am Acad Child Adolesc Psychiatry 31:539-546

5. Loeber R, Green SM, Keenan K, Lahey BB (1995) Which boys will fare worst? Early predictors of the onset of conduct disorder in a six-year longitudinal study. J Am Acad Child Adolesc Psychiatry 34:499509

6. Cohen P, Flory M (1998) Issues in the disruptive behavior disorders: Attention deficit disorder without hyperactivity and the differential validity of oppositional defiant and conduct disorders. In: Widiger $\mathrm{T}$ (ed) DSM-IV Sourcebook, vol. 4. American Psychiatric Press, Washington DC, pp 455-463

7. Maughan B, Rowe R, Messer J, Goodman R, Meltzer H (2004) Conduct disorder and oppositional defiant disorder in a national sample: developmental epidemiology. J Child Psychol Psychiatry 45:609621

8. Rowe R, Maughan B, Pickles A, Costello EJ, Angold A (2002) The relationship between DSM-IV oppositional defiant disorder and conduct disorder: findings from the Great Smokey Mountains Study. J Child Psychol Psychiatry 43:365-373

9. Sondeijker FEPL, Ferdinand RF, Oldehinkel AJ, Veenstra R, De Winter AF, Ormel J, Verhulst FC (2005) Classes of adolescents with disruptive behaviors in a general population sample. Soc Psychiatry Psychiatr Epidemiol 40:931-938

10. Loeber R, Burke JD, Lahey BB, Winters A, Zera M (2000) Oppositional defiant and conduct disorder: a review of the past 10 years, Part I. J Am Acad Child Adolesc Psychiatry 39:1468-1484

11. Greene RW, Biederman J, Zerwas S, Monuteaux MC, Goring JC, Faraone SV (2002) Psychiatric comorbidity, family dysfunction, and social impairment in referred youth with oppositional defiant disorder. Am J Psychiatry 159:1214-1224

12. Lahey BB, Miller TL, Gordon RA, Riley AW (1999) Developmental epidemiology of the disruptive behavior disorders. In: Quay HC, Hogan A (eds) Handbook of the disruptive behavior disorders. Plenum Press, New York, pp. 23-48

13. Langbehn DR, Cadoret RJ, Stewart MA, Troughton EP, Yates WR (1998) Distinct contributions of conduct and oppositional defiant symptoms to adult antisocial behavior: evidence from an adoption study. Arch Gen Psychiatry 55:821-829

14. Hill J (2002) Biological, psychological and social processes in the conduct disorders. J Child Psychol Psychiatry 43:133-164

15. Greene RW, Doyle AE (1999) Toward a transactional conceptualization of oppositional defiant disorder: implications for treatment and assessment. Clin Child Fam Psychol Rev 2:129-148

16. Campbell SB (1995) Behavior problems in preschool children: a review of recent research. J Child Psychol Psychiatry 36:113-149 
17. Moffitt TE (1990) Juvenile delinquency and attention deficit disorder: Boys' developmental trajectories from age 3 to age 15. Child Dev 61: 893-910

18. Robins LN (1978) Sturdy childhood predictors of adult antisocial behavior: replications from longitudinal studies. Psychol Med 8:611-622

19. Campbell SB (1990) Behavior problems in preschool children: clinical and developmental issues. Guilford Press, New York

20. Caspi S (2000) The child is father of the man: personality continuities from childhood to adulthood. J Pers Social Psychol 78:158-172

21. Fischer M, Rolf JE, Hasazi JE, Cummings L (1984) Follow-up of a preschool epidemiological sample: cross-age continuities and predictions of later adjustment with internalizing and externalizing dimensions of behavior. Child Dev 55:137-150

22. Lacourse E, Cote S, Nagin DS, Vitaro F, Brendgen M, Tremblay RE (2002) A longitudinal-experimental approach to testing theories of antisocial behavior development. Dev Psychopathol 14:909-924

23. Mesman J, Koot HM (2001) Early preschool predictors of preadolescent internalizing and externalizing DSM-IV diagnoses. J Am Acad Child Adolesc Psychiatry 40:1029-1036

24. Pierce EW, Ewing LJ, Campbell SB (1999) Diagnostic status and symptomatic behavior of hard-tomanage preschool children in middle childhood and early adolescence. J Clin Child Psychol 28:44-57

25. Verhulst FC, Van der Ende J (1992) Six-year stability of parent-reported problem behavior in an epidemiological sample. J Abnorm Child Psychol 20:595-610

26. Moffitt TE, Caspi A, Rutter M, Silva PA (2001) Sex difference sin antisocial behavior: Conduct disorder, delinquency and violence in the Dunedin Longitudinal Study. Cambridge University Press, Cambridge

27. Strayer J, Roberts W (2004) Empathy and observed anger and aggression in five-year-olds. Soc Dev 13:1-13

28. Deater-Deckard K, Dodge KA, Bates JE, Pettit GS (1998) Multiple risk factors in the development of externalizing behavior problems: group and individual differences. Dev Psychopathol 10:469-493

29. Dodge KA (1980) Social cognition and children's aggressive behavior. Child Dev 51:162-170

30. Holmes SE, Slaughter JR, Kashani J (2001) Risk factors in childhood that lead to the development of conduct disorder and antisocial personality disorder. Child Psychiatry Hum Dev 31:183-193

31. Hay DF, Payne A, Chadwick A (2004) Peer relations in childhood. J Child Psychol Psychiatry 45:84108

32. Pope AW, Bierman KL, Mumma GH (1989) Relations between hyperactive and aggressive behavior and peer relations at three elementary grade levels. J Abnorm Child Psychol 17:253-267

33. Vitaro F, Tremblay RE, Bukowski WM (2001) Friends, friendships and conduct disorders. In: Hill J, Maughan B (eds) Conduct disorders in childhood and adolescence. Cambridge University Press, Cambridge, pp 346-376

34. Snyder J, Horsch E, Childs J (1997) Peer relationships of young children: affiliative choices and the shaping of aggressive behavior. J Clin Child Psychol 26:145-156

35. Putallaz M, Wasserman A (1990) Children's entry behavior. In: Asher SR, Coie JD (eds) Peer rejection in childhood. Cambridge University Press, New York, pp 60-89

36. Hughes C, White A, Sharpen J, Dunn J (2000) Antisocial, angry, and unsympathetic: "hard-to-manage" preschoolers' peer problems and possible cognitive influences. J Child Psychol Psychiatry 41:169-179

37. McElwain NL, Volling B (2002) Relating individual control, social understanding, and gender to childfriend interaction: a relationships perspective. Soc Dev 11:362-385

38. Crick NR, Dodge KA (1994) A review and reformulation of social information processing mechanisms in children's social adjustment. Psychol Bull 115:74-101

39. Dodge KA (1991) The structure and function of reactive and proactive regression. In: Pepler DJ, Rubin $\mathrm{KH}$ (eds) The development and treatment of childhood aggression. Lawrence Erlbaum Associates, Hillsdale, NJ, pp 201-218

40. Gouze KR (1987) Attention and social problem solving as correlates of aggression in preschool males. J Abnorm Child Psychol 15:181-197

41. Webster-Stratton C, Lindsay DW (1999) Social competence and conduct problems in young children: Issues in assessment. J Clin Child Psychol 28:25-43

42. Dodge KA, Bates JE, Pettit GS (1990) Mechanisms in the cycle of violence. Science 250:1678-1683

43. Dodge KA, Laird R, Lochman JE, Zelli A, Conduct Problems Prevention Research Group (2002) Multidimensional latent-construct analysis of children's social information processing patterns: correlations with aggressive behavior problems. Psychol Assess 14:60-73

44. Schonberg MA, Tussey JL, Stickney JA (2003) Moderators of the relationships between proactive and reactive aggression and peer rejection. Paper presented at the Biennial Meeting of the Society for Research in Child Development, Tampa, Florida 
45. Yoon JS, Hughes JN, Cavell TA, Thompson B (2000). Social cognitive differences between aggressiverejected and aggressive-nonrejected children. J School Psychol 38:551-570

46. Dodge KA, Lansford JE, Burks VS, Bates JE, Pettit GS, Fontaine R, Price JM (2003) Peer rejection and social information-processing factors in the development of aggressive behavior problems in children. Child Dev 74:374-393

47. Miller-Johnson S, Coie JD, Maumary-Gremaud A, Bierman K, Conduct Problems Prevention Research Group (2002) Peer rejection and aggression and early starter models of conduct disorder. J Abnorm Child Psychol 30:217-330

48. Kratzer L, Hodgins S (1999) A typology of offenders: a test of Moffitt's theory among males and females from childhood to age 30. Crim Behav Ment Health 9:57-73

49. Moffitt TE, Caspi A, Dickson N, Silva PA, Stanton W (1996) Childhood-onset versus adolescent-onset antisocial conduct in males: natural history from age 3 to 18. Dev Psychopathol 8:399-424

50. De Winter AF, Oldehinkel AJ, Veenstra R, Brunnekreef JA, Verhulst FC, Ormel J (2005) Evaluation of non-response bias in mental health determinants and outcomes in a large sample of pre-adolescents. Eur J Epidemiol 20:173-181

51. Moffitt TE, Caspi A (2001) Childhood predictors differentiate life-course persistent and adolescentlimited antisocial pathways among males and females. Dev Psychopathol 13:355-375

52. Achenbach TM (1991) Manual for the Child Behavior Checklist/4-18 and 1991 profile. University of Vermont, Burlington, VT

53. Achenbach TM (1991) Manual for the youth self-report and 1991 profile. University of Vermont, Burlington, VT

54. Achenbach TM, Dumenci L, Rescorla LA (2003) DSM-oriented and empirically based approaches to constructing scales from the same item pools. J Clin Child Adolesc Psychol 32:328-340

55. Wolke D, Woods S, Bloomfield L, Karstadt L (2000) The association between direct and relational bullying and behavior problems among primary school children. J Child Psychol Psychiatry 41:9891002

56. Sourander A, Helstela L, Helenius H, Piha J (2000) Persistence of bullying from childhood to adolescence - a longitudinal 8-year follow-up study. Child Ab Negl 24:873-881

57. Sutton J, Smith PK, Swettenham J (1999) Bullying and " theory of mind": a critique of the "social skills deficit", view of anti-social behavior. Soc Dev 8:117-127

58. Wolke D, Stanford K (1999) Bullying in school children. In: Messer D, Millar S (eds) Developmental psychology. Arnold, London, pp 341-360

59. Farrington D (1993) Understanding and preventing bullying. In: Tonry M (ed) Crime and Justice, vol. 17. University of Chicago, Chicago, pp 381-458

60. Olweus D (1999) Norway. In: Smith PK, Morita Y, Junger-Tas J, Olweus D, Catalano R, Slee P (eds) The nature of school bullying: a cross-national perspective. Routledge, London, pp 28-48

61. Austin S, Joseph S (1996) Assessment of bully/victim problems in 8-11 year olds. Br J Educ Psychol 66:447-456

62. Kumpulainen K, Rasanen E, Henttonen I, Almqvist F, Kresanov K, Linna SL, Moilanen I, Piha J, Puura K, Tamminen T (1998) Bullying and psychiatric symptoms among elementary school-age children. Child Ab Negl 22:705-717

63. Veenstra R, Lindenberg S, Oldehinkel AJ, De Winter AF, Verhulst FC, Ormel J (2005) Bullying and victimization in elementary schools: a comparison of bullies, victims, bully/victims, and uninvolved preadolescents. Dev Psychol 41:672-682

64. Wellman HM, Liu D (2004) Scaling of theory of mind tasks. Child Dev 75:523-541 